\title{
Design scheme and operating principle of a centrifugal seed distributor of a pneumatic grain seeder
}

\author{
Azamat E. Bogus ${ }^{1, *}$ and Alina Vyshebabina ${ }^{1}$ \\ ${ }^{1}$ Kuban State Agrarian University named after I.T.Trubilin, 350044, Krasnodar, Russia
}

\begin{abstract}
The disadvantages of existing distribution systems of pneumatic grain seeders are presented. A design scheme of a centrifugal seed distributor is proposed and the principle of its operation, the causes of uneven distribution, and the history of the development of grain seeders, in which the principle of central seed dosing is implemented, are described. The analysis of designs of pneumatic grain seeders is carried out, the types of their dosing and distribution systems are revealed.
\end{abstract}

\section{Relevance of research}

There are many different pneumatic grain seeders that implement the principle of centralized seed dosing, but they have a high uneven distribution of seeds that does not meet the agrotechnical requirements.

\section{Design schemes of distribution systems}

The design features of pneumatic seeders have a significant impact on the uniformity of seed distribution between the seed lines. Vertical distribution systems with a mushroom shape are mostly used (Figure 1) [1, 5, 6, 7, 8].

In vertical systems, seeds from the hopper 1 are delivered by a coil metering device to the diffuser 7, from where they are transferred by air flow through the material pipeline 9 to the vertical column to the distribution head of the first stage 12 . And then through the material lines 10 , the seeds fall into the distribution heads of the second stage 13, and from there through the seed lines 15 to the plowshares 16. If the system is single-stage, then the seed material after the distribution head of the first stage immediately enters the seed pipelines $[9,10,11]$.

\footnotetext{
* Corresponding author: azamat089@gmail.com
} 


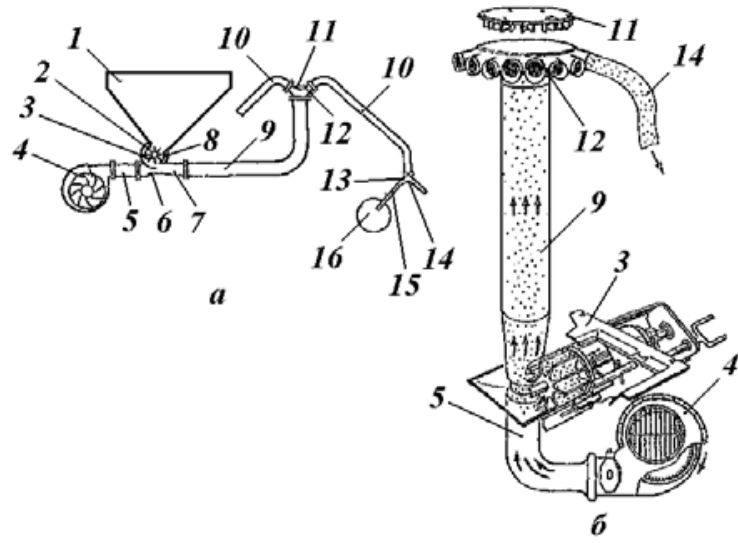

$\mathrm{a}$ - two-stage; $\mathrm{b}$ - single-stage;

1 - hopper; 2 and 8 - sealings; 3 - dosing device; 4 - fan; 5 - air duct; 6 - confuser; 7 - diffuser; 9 and 10 - general and connecting material lines; 11 and 14 - reflectors of the first and second stages; 12 and 13 - distribution head of the first and second stages; 15 - seed line; 16 - plowshare

Fig. 1. Vertical distribution system of a pneumatic grain seeder

When transporting seeds through a pneumatic pipeline, the air velocity is $16 \ldots 27 \mathrm{~m} / \mathrm{s}$, and the coefficient of mass consumption concentration $\mu=1.0-1.5$.

Vertical distribution systems provide low uniformity of seed distribution along the seed lines, and can also damage them after hitting the reflecting surface.

We have proposed a design scheme for a centrifugal seed dispenser of a pneumatic grain seeder (Figure 2) consisting of a chamber 1 in the form of a body of rotation with a convex bottom 2, two supply lines 3 symmetrically connected tangentially with its upper part and discharge pipelines 5 connected to an annular section of the bottom [3].

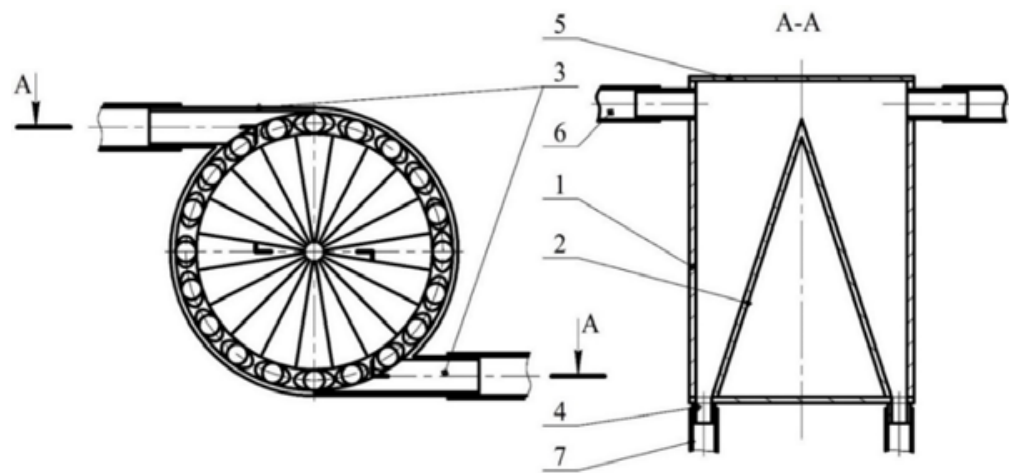

1 - chamber; 2 - convex bottom; 3 - supply pipes; 4 - discharge pipes; 5 - cover; 6 - supply pneumatic pipeline; 7 - seed pipeline

Fig. 2. Scheme of centrifugal deed dispenser

The centrifugal seed dispenser of the grain pneumatic seeder works as follows. Seeds from two pneumatic pipelines 6 through the supply pipes 3 enter the chamber 1 , under the influence of centrifugal force, they are involved in a rotational movement around the axis of the dispenser [2]. Settling on the bottom of the dispenser, the seeds fall into the discharge pipelines 4 , from where they are sent to the plowshares by seed ducts. 
The uneven distribution of seeds by a pneumatic grain seeder is largely influenced by the uniformity of the seed distribution in the cross-section of the supply pipelines. Since the design of the centrifugal seed dispenser contains two supply pipelines (Figure 3), the design of the pneumatic grain pneumatic seeder has a flow divider 4 , in front of which a turbulator 3 is installed that allows us to distribute the seeds in the cross section of the supply pipelines evenly. Figure 3 shows a design diagram of a pneumatic grain seeder with a centrifugal distribution system, operating as follows.

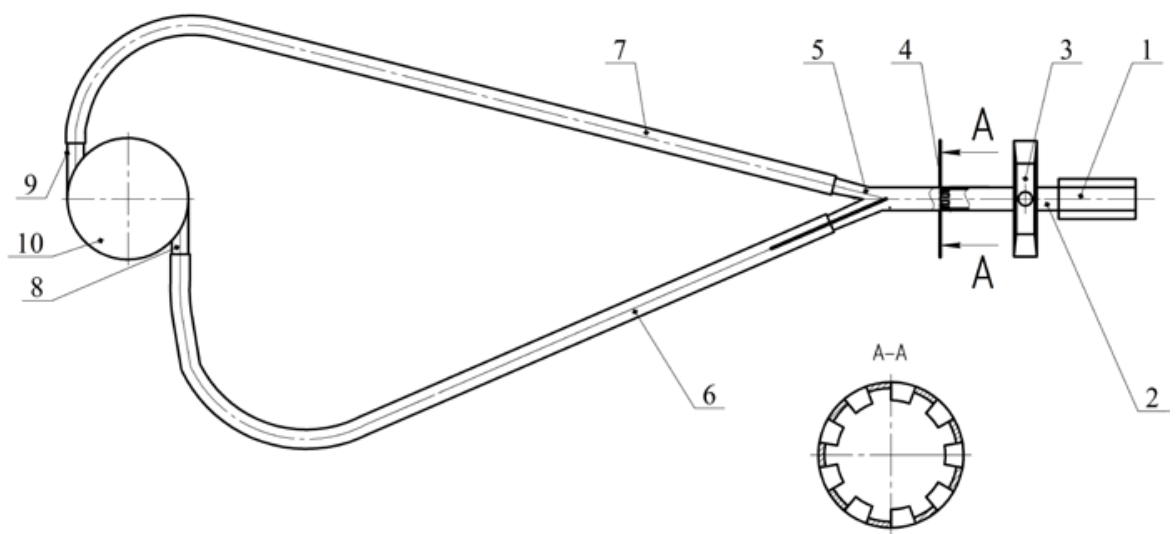

1 - fan; 2 - main pneumatic pipeline; 3 - hopper with a dosing system; 4 - turbulator; 5 - divider of flow; 6 and 7 -material pipelines; 8 and 9 - supply pipes; 10 - centrifugal dispenser

Fig. 3. Scheme of a centrifugal distribution system of a grain seeder

Seeds from the hopper by the metering system 3 are introduced into the air flow of the main material pipeline 2, then the flow of the grain-air mixture is leveled using the turbulator 4 and the flow divider 5 is divided into two material pipelines 6 and 7 . Then the seeds through the parts of supply pipes 8 and 9 enter the chamber of the centrifugal distributor 10 .

To justify the design scheme of the centrifugal dispenser, the minute seed supply was calculated at different seeding rates and speeds of the seeder operation, taking into account the gripping width of according to the expression [4]:

$$
q=\frac{0.277 Q V B t}{10000}
$$

where $q$ - minute seed supply, $\mathrm{kg} / \mathrm{min}$;

$Q$ - rate of seed sowing, $\mathrm{kg} / \mathrm{ha}$;

$V$ - speed of a seeder operation, $\mathrm{km} / \mathrm{h}$;

$B$ - gripping width of a seeder, $\mathrm{m}$;

$t$ - time of operation, c.

With a seeding unit width $B=8.4 \mathrm{~m}$ of speed, movement $V \in[8 ; 12] \mathrm{km} / \mathrm{h}$ and a seeding rate $Q \in[150 ; 250] \mathrm{kg} / \mathrm{ha}$, the minute supply will fluctuate in the range $q \in[16 ; 42]$ $\mathrm{kg} / \mathrm{min}$.

The use of the proposed design scheme of the centrifugal seed dispenser will improve the quality of sowing, the labor intensity of maintenance of the pneumatic grain seeder will decrease. 


\section{Conclusions}

The analysis of the designs of pneumatic grain seeders showed that most of the produced sowing machines use vertical distribution devices with fixed reflective surfaces, the main disadvantage of which is the high unevenness of the seed distribution along the seed lines.

Pneumatic grain seeders are the most promising direction of development of separate aggregate sowing machines. To improve the quality performance of pneumatic grain seeders, it is necessary to use centrifugal distribution systems in their designs, which reduce the uneven seed distribution between seed lines.

\section{References}

1. Astakhov V.S. Analysis of pneumatic centralized sowing systems // Tractors and agricultural machines. - 1997. - №. 10. - pp. 33-34.

2. Bogus A. Analytical study of uneven distribution of seeds by a centrifugal distributor/ A. Bogus // E3S Web of Conferences: International Conference on Modern Trends in Manufacturing Technologies and Equipment - 2020.

3. Bogus A. Investigation of the kinematics of seed movement in the centrifugal distributor of a pneumatic seeder / A. Bogus // E3S Web of Conferences: International Conference on Modern Trends in Manufacturing Technologies and Equipment 2020. https://doi.org/10.1051/e3sconf/202019301017.

4. Bogus A. Substantiation of the technological scheme of pneumatic grain seeder of subsurface dense sowing / Bogus A. E., Kuzmenko A. D. // E3S Web of Conferences. - 2019. - P. 00040.

5. K. A. Sokht, E. I. Trubilin, V. I. Konovalov, Statistical methods of researches of processes and machines in agribusiness (Krasnodar: KubSAU, 2016)

6. Klenin N.I. Agricultural machines: manual / N. I. Klenin, S. N. Kiselev, A. G. Levshin (M.: KolosS, 2008).

7. Kryuchin N.P. Development of a pneumatic seeder for sowing herbs-phytomeliorants // In thecollection: Tehnogennaja i prirodnaja bezopasnost' materialy IV Vserossijskoj nauchno-prakticheskoj konferencii [Technogenic and natural safety materials of the IV All-Russian Scientific and Practical Conference]. Saratov State Agrarian University named after N.I. Vavilov Publ. 2017. pp. 253-257.

8. N. P. Kryuchin, O. N. Serobaba, D. N. Kotov, A. N. Kryuchin Pat. №181167, Russian Federation, IPC A01C 7/00. Screw sowing apparatus. - №2018106609, declared 02/21/2018; publ. 07/05/2018 Bull. №19

9. Kulen A. Modern agricultural machinery [Text] / A. Kulen, Kh.Kuipers. Translation of A.E.Gabrielyan; under edition and with introduction Yu. A. Smirnov, M.: Agropromizdat, 1986.

10. N. P. Kryuchin, O. N. Serobaba, D. N. Kotov, A. N. Kryuchin Pat. №181167, Russian Federation, IPC A01C 7/00. Screw sowing apparatus. - №2018106609, declared 02/21/2018; publ. 07/05/2018 Bull. №19

11. Yatskul A. I., Lemière J. P. Experimental determination of flow concentration for pneumatic conveying systems of air-seeders // INMATEH-Agricultural Engineering. 2014.- №.44(3). - pp. 17-24. 